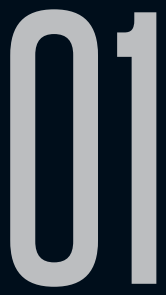

\title{
ENTREVISTA COM ROBERTO DE SOUSA CAUSO
}

\author{
Flavio García (UERJ) \\ Marisa Martins Gama-Khalil (UFU)
}

Recebido em 13 ago 2017. Flavio García é Pós-Doutor pela UC (2016), UFRGS (2012) Aprovado em 23 ago 2017. e UFRJ (2008), Doutor pela PUC-Rio (1999) e Mestre pela UFF (1995). Professor Associado da UERJ, atua no Mestrado e Doutorado na área de Estudos de Literatura. Foi o primeiro coordenador do GT ANPOLL "Vertentes do Insólito Ficcional" (julho de 2011 a junho de 2016) e é líder do GP Diretório de Grupos do CNPq "Nós do Insólito: vertentes da ficção, da teoria e da crítica" (desde 2001). Vem publicando variados títulos (livros de autoria própria ou organizados, capítulos de livro e artigos em periódicos) sobre as "vertentes do insólito ficcional" no Brasil e no exterior.

Marisa Martins Gama-Khalil - que possui doutorado em Estudos Literários pela UNESP e pós-doutorado pela Universidade de Coimbra, é professora da UFU, atuando na Graduação em Letras, no Programa de Pós-Graduação em Estudos Literários e no Mestrado Profissional em Letras. É pesquisadora Produtividade em Pesquisa CNPq e possui diversas publicações artigos em revistas científicas e livros - na área da Literatura Fantástica, bem como algumas organizações de revistas e livros na referida área, como a Revista Letras \& Letras e os e-books História e ficção no universo do fantástico (EDUFU) e Vertentes do Insólito Ficcional: Ensaios I (Dialogarts). Lidera o Grupo de Pesquisas em Espacialidades Artísticas. 


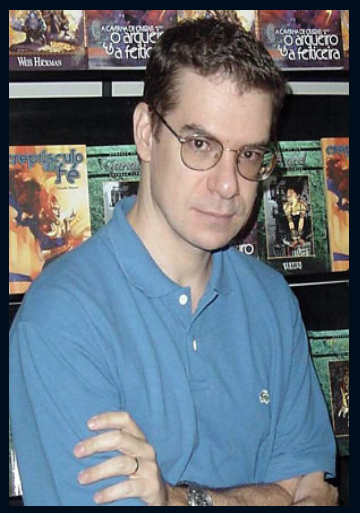

Roberto de Sousa Causo, segundo se lê nos resultados mais elementares de qualquer pesquisa digital, logo no início da entrada de seu nome na Wikipédia, "é um escritor e editor brasileiro de ficção científica, fantasia e horror", nascido em 27 de outubro de 1965. Ainda que essa predicação básica, a ele atribuída, corresponda à mais absoluta verdade, o acesso ao link da Wikipédia denuncia que as informações contidas na página estão defasadas já desde há muito. Outra pesquisa junto ao site de qualquer boa livraria nacional, que não se limite a apresentar apenas os títulos que estejam disponíveis para venda, mas que liste, no geral, todas as obras correlacionadas ao nome do autor pesquisado, trará, em seus resultados, uma boa lista de livros cuja autoria ou organização vincula-se a Roberto de Sousa Causo.

Seu primeiro livro foi a coletânea de histórias $A$ dança das sombras (1999), lançada em Portugal na coleção Caminho Ficção Científica. A sua estreia no universo literário aconteceu com o livro Fiç̧ão cientifica, fantasia e horror no Brasil: 1875 a 1950. Livro esgotado do acadêmico, Doutor em Estudos Linguísticos e Literários e Inglês (USP, 2013), com a tese intitulada Ondas nas praias de um mundo sombrio: new wave e cyberpunk no Brasil. Os "Agradecimentos" do livro dirigem-se à Fundação de Amparo à Pesquisa do Estado de São Paulo (FAPESP), cujo projeto de iniciação científica teria custeado, com bolsa, de junho de 1995 a fevereiro de 1997. Chegando ao final de quatro páginas de agradecimentos, nas quais surgem nomes como João Luiz Machado Lafetá, João Alexandre Barbosa, João Adolfo Hansen, Lynn Mário Trindade Menezes de Souza, Heitor Megale, dentre outros tantos mais, Causo afirma algo que, hoje, já não é tão mais verdadeiro: "Os assuntos ficção científica, fantasia, horror e fantástico têm muito pouca penetração nas universidades". Muito, com certeza, dessa transformação que, em parte, o 
desmente devemos a estudiosos e artistas como ele. Enfim, Ficção cientifica, fantasia e horror no Brasil: 1875 a 1950, que merece nova edição, é um título essencial para aqueles que se dedicam aos estudos dos "fantásticos, parafantásticos, metafantásticos, pseudofantásticos", ou seja, de toda uma diversidade de ficção que caminha, par e passo, junto do que, grosso modo, vimos chamando de fantástico, sem muito rigor em distinguir especificidades.

Logo no ano seguinte, 2004, aparece no mercado editorial A sombra dos homens: a saga de Tajarê Livro I. Cabe alertar ainda que Causo tem um grande número de textos publicados em revistas e antologias organizadas por outras pessoas, desde 1989, tornando-o um dos autores mais experientes da área, ainda em atividade. Em 2006, dois novos títulos de ficção vêm a público: $A$ corrida do rinoceronte $\mathrm{e}$ Glória sombria. Passados mais dois anos, Causo lança em 2008 O par: uma novela amazônica, um de seus poucos títulos mais antigos, sem nova edição, ainda disponíveis para compra.

Nesse mesmo ano de 2008, lança a antologia Os melhores contos brasileiros de ficção científica, seguida, em 2009, de Os melhores contos brasileiros de ficção científica e, em 2011, de As melhores novelas brasileiras de ficção científica.

O ano de 2009 foi bastante próspero para o ficcionista e antologista. Nesse ano, saíram a antologia Rumo à fantasia e o romance Anjo de dor, além dos e-books Selva Brasil, Brinquedos mortais: um herói para Afrodite, Space Opera: A alma de um mundo e Um toque do real: óleo sobre tela, permitindo que o leitor tenha acesso digital à sua obra.

Causo estreou na mídia digital em 2013, lançando Voo sobre o mar da loucura e Terra verde, que já haviam aparecido em livro. No ano seguinte, ele 
tornaria a investir no suporte digital, publicando Encontro no vigésimo-oitavo andar, que, como os demais, também já aparecera em papel, tanto no seu livro de contos $A$ dança das sombras, como em uma edição para bancas de revista.

Em 2015, juntamente com os cinco títulos publicados digitalmente, o ficcionista retorna às edições impressas, com Shiroma, matadora ciborgue. No outro ano, 2016, Causo voltaria à mídia digital, lançando Excalibur: A memória da espada.

Sua mais recente publicação data de 2017 e está disponível em forma impressa. Trata-se de Mistério de Deus, parte de uma série de romances de horror iniciada com Anjo de dor, prometendo novos volumes por vir.

Entre 1989, quando se registra a primeira publicação ficcional assinada por Causo, e 2017, quando se verifica sua última obra lançada, não se pode dizer que ele tenha abandonado, de todo, o seu lado acadêmico. Há, em muitos volumes disponíveis no mercado de novos ou de usados, prefácios, apresentações, introduções em que Causo exercita seu lado crítico, voltando às suas bases de formação, graduado, em 2004, em Inglês/Português pela Universidade de São Paulo (USP), onde desenvolveu pesquisas desde a graduação, tendo vindo a defender seu doutorado em 2013. Além disso, ensaios acadêmicos de sua autoria têm aparecido em revistas específicas e em antologias acadêmicas, no Brasil e no exterior.

Para aqueles que se interessam, como leitores de ficção, teóricos, críticos, a obra desse escritor, antologista, teórico, crítico e editor de ficção científica, fantasia, horror e, por que não, de fantástico, em lato sensu, abarcando suas para, meta, pseudomanifestações, é uma referência obrigatória. 
P.: Roberto, você tem uma história de acadêmico, graduado em Letras (2004), com doutorado em Letras (2013), por uma das mais, senão a mais importante, universidade brasileira, a Universidade de São Paulo (USP), tendo convivido com importantes nomes dos estudos de literatura. Sua primeira publicação, Ficção cientifica, fantasia e horror no Brasil: 1875 a 1950, datada de 2003 (Belo Horizonte: Editora UFMG), é um compêndio que mescla teoria, crítica e historiografia literárias, cuja origem teria sido uma pesquisa de iniciação científica orientada por João Lafetá. O acadêmico se alterna com o ficcionista.Em sua vida, quem surgiu primeiro, o acadêmico ou o ficcionista?

R.: O ficcionista. Depois de um falso início em 1983, escrevi meu primeiro conto em 1985, e como ele foi finalista do Prêmio Fausto Cunha, um concurso promovido pelo Clube de Ficção Científica Antares, de Porto Alegre, achei que eu poderia funcionar como escritor. Desde 1989, publiquei profissionalmente pelo menos uma história por ano, e frequentemente mais do que uma.

P.: Por que você optou pela produção ficcional, em detrimento da acadêmica?

R.: Na verdade, tenho ensaios acadêmicos publicados em revistas como Extrapolation, Magma (da FFLCH/USP), Science Fiction Studies (em parceria com M. Elizabeth Ginway) em antologias acadêmicas ou de introdução universitária como Volta ao mundo da ficção científica (UFMS, 2007); New Boundaries in Political Science Fiction (University of South Carolina Press, 2008); e Reading Science Fiction (Palgrave Macmillan; 2009). 
Também nos journals eletrônicos Zanzalá e Alambique (University of South Florida), sendo que pertenço aos conselhos editoriais desses dois, que se especializam em ficção científica e fantasia brasileira e latino-americana, e para os quais faço peer-review. Mas, de fato, minha preferência pessoal está no meu primeiro amor, a escrita ficção. Não quer dizer que parei de pesquisar FC, fantasia e horror. Minhas antologias dos melhores contos e novelas brasileiras de ficção científica, organizadas para a Devir Brasil, são uma extensão da minha pesquisa nessa área (elas descobrem histórias, alinhavam temas e tendências e articulações com a cultura brasileira e a recepção da $\mathrm{FC}$ como gênero internacional). E junto à Devir, editei, como free-lancer, os livros acadêmicos Visão alienígena: ensaios sobre fiç̧ão científica brasileira (2010), de M. Elizabeth Ginway, da University of Florida em Gainesville e a principal pesquisadora mundial de FC brasileira, e Atmosfera rarefeita: a ficção científica no cinema brasileiro (2014), de Alfredo Suppia, da Unicamp. Além disso, traduzi ensaios de Ginway, e o primeiro livro dela, Fiç̧ão científica brasileira: mitos culturas e nacionalidade no país do futuro, publicado no Brasil pela Devir em 2005. Então, pode-se dizer que, mesmo sem um cargo de docente, mantenho uma atuação na área. E não mencionei aqui os vários cursos de extensão e oficinas que já ministrei.

P.: O ficcionista, que vivia em sua alma, serviu ao acadêmico, e em que medida, o acadêmico colabora com o ficcionista?

R.: Foi o pesquisador - primeiro informal e mais tarde com formação universitária - que serviu ao ficcionista. Isso se dá porque desde quando eu era apenas um fã de ficção científica - e sou um fã 
ativo desde 1983 -, entender o lugar e a aceitação do gênero são importantes para o meu posicionamento como leitor e, mais tarde, como escritor. Escrever ficção científica (e talvez em menor grau, fantasia e horror) no Brasil é atividade com poucas possibilidades de sucesso de vendas e de crítica. Não existe, de fato, muita recompensa a quem se dedicar a esse campo literário. Para mim, sempre foi importante entender os mecanismos que formam essa realidade, para que eu tivesse consciência do caminho que poderia trilhar e que expectativas realistas poderia ter. A outra questão é que, pesquisando esses gêneros e valorizando-os como objeto de pesquisa legítimo e enriquecedor do contexto acadêmico brasileiro, haveria a possibilidade de também valorizar, em alguma medida, a produção ficcional nacional, nesse mesmo campo. Devo dizer ainda que sou um dos poucos escritores de FC e fantasia que se apoia conscientemente na tradição local desses gêneros, num diálogo intertextual com autores e tendências do passado. Por exemplo, enfocando a floresta amazônica como o fizeram antes Gastão Cruls, Menotti del Picchia e Jeronymo Monteiro. Minhas séries Saga de Tajarê, de fantasia heroica; Aventuras de Ulisses Brasileiro, de ficção científica steampunk; e Shiroma, Matadora Ciborgue, de space opera, trazem esse diálogo de forma explícita. Outro exemplo: escrevendo minhas próprias histórias tupinipunks (cyberpunk tupiniquim) na linha de Alfredo Sirkis e Ivanir Calado.

P.: Há alguma expectativa sua em retornar à academia, ainda que apenas como crítico?

R.: Como observei acima, mantenho uma atividade como pesquisador independente, mas cogito sim, trabalhar na área como docente de estudos literários. Para além disso, tenho mais 
dois ensaios aguardando publicação, e outros em planejamento (sobre a novela "Zanzalá", de Afonso Schmidt, e sobre a ficção pulp brasileira). E o projeto de seguir com as antologias dos melhores contos e novelas brasileiras continua vivo.

P.: Em seus agradecimentos no seu livro de não ficção, você afirma que "Os assuntos ficção científica, fantasia, horror e fantástico têm muito pouca penetração nas universidades". Hoje, há um Grupo de Trabalho na Associação Nacional de Programas de Pós-Graduação e Pesquisa em Letras e Linguística (ANPOLL) dedicado às "Vertentes do Insólito Ficcional", bem como há diversos Grupos de Pesquisa certificados no Diretório de Grupo do Conselho Nacional de Desenvolvimento Científico e Tecnológico (CNPq), estudando essas manifestações que você elencou, além de outras mais próximas a elas. Pululam periódicos acadêmicos, como este, além de muitos números de outras revistas, dedicados exclusivamente ao tema, chegando, por vezes, a coincidir, ao mesmo tempo, uma dezena de chamadas equivalentes. Acontecem eventos científicos, do mais extremo sul ao mais extremo norte do Brasil, cujo tema central ou alguns de seus eixos abordam a ficção científica, a fantasia, o horror, o fantástico ou o gótico, por exemplo. Muitos têm sido os livros de teoria ou crítica, nacionais ou traduzidos, publicados em torno dessa mesma questão. Hoje, em 2017, você repetiria aquela mesma frase?

R.: Não, em absoluto. E tenho dito há algum tempo que se efetiva uma "troca da guarda" no ambiente acadêmico brasileiro, com a entrada nas universidades de grande número de jovens pesquisadores - como Ramiro Giroldo, Adriana Amaral, 
Marcos Vilela, Suzane Lima Costa, Alfredo Suppia, Elton Furlanetto, Rodolfo Londero, Claudia Fusco, Roberto Belli, Carlos Alberto Machado, Edgar Smaniotto, Vitor M. Vívolo e vários outros - que têm contribuído muito para o avanço desse campo crescente. A troca da guarda se dá porque são jovens pesquisadores que chegaram à universidade guardando interesse e fascínio pela FC e fantasia surgidos do seu hábito de consumir literatura dentro desses gêneros, além de histórias em quadrinhos, audiovisual e jogos do tipo RPG e videogame. Eles não se intimidaram com a predisposição arraigada na universidade brasileira, de condenar a "cultura de massa" e a "indústria cultural", e desbravaram esse campo com muita determinação e energia. Eu também não repetiria o título do último capítulo de Ficção científica, fantasia e horror no Brasil, "A pulp era que não houve" - o trabalho recente (2009) do Prof. Athos Eichler Cardoso comprovou que o mercado para revistas populares de ficção, chamadas por ele de "revistas de emoção", as pulps brasileiras, existiu com grande intensidade entre as décadas de 1930 e 60. O que não houve foi uma participação expressiva dos autores locais, nesse mercado dominado pelas traduções.

P.: O que você acha que mudou de lá para cá?

R.: Esses jovens acadêmicos foram premiados com um contexto editorial que tornou FC, fantasia e horror determinantes para a publicação de literatura no Brasil e no mundo, um fenômeno que exige estudo e análise. Além disso, a florescente cultura digital se comunica com tais gêneros, sendo um fator talvez ainda mais fecundo para a instalação desses estudos no Brasil. 
Mas a troca da guarda ainda não se completou, em minha opinião, porque o lugar dos gêneros especulativos pode e deve ser ainda mais central nos estudos acadêmicos. Ela vai se completar quando os jovens a que me refiro se tornarem orientadores dos mestres e doutores da nova geração, já livres de preconceitos e dos conceitos teóricos negativos que atrelavam os gêneros populares apenas a "cultura de massa" e "indústria cultural". Lembro ainda que a FC foi pesquisada no Brasil, no âmbito universitário, desde a década de 1970. Vide A ficção do tempo, de Muniz Sodré, que dispensa o gênero como subliterário e impertinente. Mas raramente na esfera dos cursos de Letras - Comunicações, Filosofia, Pedagogia e História concentravam a maioria, com Letras se mantendo como a torre de marfim do elitismo literário. Eu realmente espero que o cerco a essa torre a coloque abaixo, no futuro próximo. Já passou da hora.

P.: Na sua opinião, quais outras variantes da ficção (teatro, cinema, televisão etc.) teriam contribuído para esse novo quadro que se constata tanto na academia, quanto no mercado?

R.: Aquelas do audiovisual (cinema e televisão, principalmente), que hoje reúnem muitos pesquisadores. Alfredo Suppia é a autoridade mundial em cinema brasileiro de ficção científica, mas há muita gente estudando cinema de FC e fantasia, seu potencial didático no ensino das ciências, e em suas expressões culturais - na forma dos diversos fandoms existentes. Adriana Amaral e Carlos Alberto Machado são exemplos de estudiosos dos fandoms brasileiros. Filmes e séries de sucesso cativam e educam jovens escritores nos contornos dos gêneros - com 
erros e acertos. As vendas das séries literárias Harry Potter e $O$ Senhor dos Anéis, propelidas por suas respectivas adaptações cinematográficas, foram um divisor de águas. É bom lembrar que a literatura no suporte eletrônico também tem chamado muito a atenção de pesquisadores locais e internacionais, pela novidade do fenômeno e pelo modo como ela contornaria as expectativas literárias e mercadológicas usuais. Essa situação resultou em uma das características mais marcantes da Terceira Onda da FC Brasileira, iniciada em 2004 na rede social do Orkut - o peso da internet como articuladora e difusora de FC e fantasia brasileira. A democratização da livre expressão trazida pela internet também resultou na demanda atual por maior diversidade étnica e sexual, refletida no Movimento Irradiativo dentro da ficção especulativa brasileira - uma proposição dos escritores Jim Anotsu, Allya e Ana Cristina Rodrigues. A indústria do livro também tem reagido a isso, publicando blogueiros e youtubers, muitos dos quais associados aos gêneros em questão, na esfera jovem adulta ou infanto-juvenil.

P.: Para você, essas vertentes ficcionais que estavam na margem passaram ao centro?

R.: Elas se aproximaram muito do mainstream, mas ainda não o substituíram ou se fundiram a ele. A ficção modernista e pós-modernista nacional ainda detém os espaços de maior prestígio no sistema literário e acadêmico - juntamente, talvez, com fenômenos literário-sociais como o movimento Literatura Marginal, de Ferréz (que, curiosamente, também é fã de ficção científica). Eu investiguei os atritos, ainda vivos, entre mainstream e a ficção de gênero, na minha tese de doutorado, 
orientada pelo Prof. Lynn Mário. Ainda quanto a essa questão, é fundamental destacar a atuação de Nelson de Oliveira, autor e antologista aglutinador da Geração 90, que no século XXI se voltou para a escrita (sob o pseudônimo de "Luiz Bras") e promoção da ficção científica como meio de renovação da literatura brasileira, que, na visão dele, passa há algum tempo por um esgotamento dos seus modelos. A aproximação entre FC e o mainstream literário nacional foi promovida por Oliveira na sua coluna "Ruído Branco" no jornal literário Rascunho, de Curitiba, e no Projeto Portal de revistas lançadas em regime de cooperativa. Também em várias antologias, em especial Futuro Presente (Record, 2009) e Todos os Portais (Terracota, 2012). Certamente, ele tem feito muito para realizar essa aproximação. Mas aqui, mais uma vez, lembro que ocorreu uma instância anterior de encontro semelhante - durante a ditadura militar, com o Ciclo de Utopias e Distopias (1972 a 1982), em que muitos autores do mainstream (incluindo Ignácio de Loyola Brandão, Márcio Souza, Herberto Salles e Chico Buarque) buscaram recursos da FC para realizar uma denúncia do regime autoritário, à tecnocracia, e à censura dos costumes e da sexualidade livre. Finda a ditadura, o casamento entre a FC e o mainstream kafkiano de então terminou em discreto divórcio, longe das colunas sociais. Espero que a proposta de Oliveira renda mais frutos, especialmente no sentido de firmar a legitimidade da ficção científica como um gênero de importância para as letras nacionais. Hoje, Oliveira tenta investir a FC com o caráter boêmio e contestador das literaturas marginais também necessário para sacudir a literatura brasileira atual. 


\section{P.: Você acha que elas deixaram de se enquadrar naquilo que se} chama de "literatura menor"?

R.: Foram muito valorizadas pelas circunstâncias que descrevi acima, mas não se deve subestimar a capacidade do establishment literário de se encastelar nos seus valores e de reagir à mudança. Outro dia, Gumercindo Rocha Dorea, o mais importante editor da Primeira Onda da Ficção Científica Brasileira (1957 a 1972), me disse que o turbulento quadro brasileiro de hoje seria um prato cheio para a literatura mainstream - mas a moda literária atual é a autoficção intimista e não o romance panorâmico, político ou policial. O argumento de Nelson de Oliveira, de que a FC expressa melhor a realidade atual - marcada pela conectividade e instantaneidade da comunicação, pela mudança climática provocada pelo aquecimento global, e pela especulação neoeugenista do transhumanismo - igualmente passa ao largo. (Note-se aí que Nelson de Oliveira escreveu dois romances tupinipunks do que tenho chamado de "literatura pósmensalão": Distrito Federal e Não Chore. Mas o primeiro dessa tendência deve ter sido o premiado O Rei do Cheiro, de João Silvério Trevisan. Precisamos de mais!)

P.: Na academia, vemos duas diferentes correntes de estudiosos do gótico, do fantástico, da ficção científica, do horror etc. que nem sempre convivem harmoniosamente entre si. Uma dessas correntes defende os limites interseccionais entre cada uma dessas vertentes da ficção, procurando delimitá-las em suas especificidades. Outra opta por diluir as fronteiras limítrofes e advoga a permeabilidade entre essas manifestações, 
centrando-se, via de regra, no aspecto insólito ou metaempírico que as demarca. Ambas as correntes vêm demonstrando força e ampliando seus espaços de atuação, o que, na verdade, acaba enriquecendo ainda mais essas variedades da ficção não absolutamente realista, tributárias do metaempírico, que se nutrem do sobrenatural, do extraordinário, do que foge à lógica racional e aristotélica. O acadêmico Roberto de Sousa Causo, comporia com qual das duas correntes?

R.: Eu tendo a ser eclético e inclusivista, mas não nego que me identifico com a primeira, porque minha pesquisa tem um lado "taxonômico" muito acentuado, em que persigo as linhagens ficcionais da FC, da fantasia e do horror e os seus diversos subgêneros. Num primeiro momento, acho que a validade disso esteve em informar não apenas das correntes e diferenciações inerentes a cada gênero, mas também de firmar didaticamente os conceitos, linhas de pesquisa e hipóteses mais comuns da pesquisa de origem angloamericana. Uma área que, inclusive, partilha da contribuição feita por fãs e autores dos gêneros em questão - sendo portanto, mais democrática e menos autoritária do que outras mais teóricas e exclusivas de investigação propriamente acadêmicas. Daí minha ênfase, por exemplo, nas questões de política literária discutidas na minha tese. Hoje, meu empenho taxonômico e historiográfico também é um esforço (modesto e assumidamente minoritário) de correção de vícios de pesquisa e de atitude que se instalaram entre muitos, durante essa "troca da guarda" de que falei. Um outro aspecto está no fato de que, até certo ponto, as linhas limítrofes entre 
ficção científica, fantasia e horror sempre estiveram nubladas, a partir mesmo da inserção inicial desses gêneros no século XIX - é o que mostra minha pesquisa para Ficção científica, fantasia e horror no Brasil -, tornando a distinção entre as duas correntes que você descreve inconsistente perante a história da dinâmica desses gêneros. Scott McKraken, em Pulp: Reading Popular Fiction, já dizia que as definições e demarcações dos gêneros populares são contingentes e interrelacionais - um gênero só é definido a partir da sua dinâmica relativa a outros gêneros, e, principalmente, ao mainstream. Isso não quer dizer que não existam; são apenas dinâmicas e contraditórias, em constante fluxo. E sempre foram assim. Por isso, às vezes enxergo o clamor atual pela mistura de gêneros como um esforço retórico direcionado a objetivos específicos, de firmar uma ou outra tendência literária ou teórica, em detrimento de outras. O que importa para mim como crítico não é tanto se a ficção científica aparece ou não misturada com o horror, por exemplo - ou com o espírito brincalhão pós-modernista - , mas o que se faz especificamente num trabalho qualquer de gêneros misturados ou de "forma pura" (se é que ela existe). Mas note que, longe daquilo que em geral o conto fantástico realiza, gêneros populares como a FC, a fantasia e o horror propõem o estranho e o inexistente (hoje) dentro de parâmetros realistas, com os quais os personagens (e o leitor, durante a leitura) conseguem interagir de maneira coerente e racional. Está enfeitiçado? Um mago tem o antídoto! Um cometa atingirá a Terra? A tecnologia espacial vai desviá-Io! Está possuído? Chame o exorcista! Por isso a ficção 
especulativa talvez seja mais subversiva - ela afirma que o real é precário e de curta duração, mas alguém saberá lidar com as divergências. O conhecimento para isso está em algum lugar, à espera, e conseguiremos operar no mundo estranho apresentado na ficção. O irracional é operável. A atitude que surge daí é bastante diversa da atitude explorada na literatura fantástica. O sujeito que aguarda à entrada do tribunal, na porta destinada apenas a ele, no conto de Kafka, vai passar a vida de joelhos no seus degraus, sem respostas nem estratégias para lidar com o guarda que não o deixa entrar. E aí, imagino, a ficção especulativa é parafantástica - no sentido antigo que chamava a literatura popular ou "de massa" (expressão que eu rejeito) de "paraliteratura", paralela e portanto com uma certa autonomia e divergência, em relação ao mainstream.

P.: A despeito do mercado, o ficcionista Roberto de Sousa Causo é mais simpático à qual das duas correntes?

R.: Como eu disse, os gêneros especulativos já apareceram misturados ou potencialmente misturados desde sua inserção no século XIX. A própria ficção científica moderna surge de um romance gótico, o Frankenstein (1818), de Mary Shelley, ele mesmo com componentes de horror e de aventura. A FC e a fantasia de aventura frequentemente recorriam ao mesmo formato - a narrativa de mundo ou raça perdida. A weird fiction de Lovecraft, Howard e outros projetava um horror cósmico, maior que a civilização humana, em mundos contemporâneos ou de fantasia. A space opera de E. E. "Doc" Smith e Edmund Hamilton se abria para o paranormal e o mítico, nas suas aventuras espaciais. $\mathrm{O}$ romance planetário de Burroughs se inspirava no esoterismo da 
Doutrina Secreta de Blavatsky. Além desses exemplos, a ficção de exploração e de aventura, o western, a ficção militar, de crime e até a love story e o erótico, e o romance psicológico ou de observação social entraram e entram constantemente na sopa especulativa. O que faço como ficcionista é adaptar e atualizar esses potenciais na minha FC, fantasia e horror. Desse modo, a Atlântida mística de Jeronymo Monteiro está nas histórias de Tajarê e de Ulisses Brasileiro (com uma pitada de pseudo-história brasileira, com vikings e minoicos tropicais), assim como uma desconstrução da superciência da raça perdida dos cretenses de Menotti del Picchia. O horror espiritualista de Anjo de Dor e de Mistério de Deus se apoia no conceito do mundo paralelo da ficção científica. A Corrida do Rinoceronte mistura fantasia contemporânea com FC. E a space opera das Lições do Matador e de Shiroma, Matadora Ciborgue, tem espaço para espiritualidade e misticismo sincréticos. Eu apenas resisto à imitação do New Weird ou da new space opera anglo-americanas por preferir minhas próprias explorações intertextuais.

P.: Para você, como acadêmico, quais seriam as melhores definições para ficção:

\section{a) gótica?}

R.: Aquela ficção que projeta uma subjetividade atormentada para o ambiente ou para as relações sociais. Um bom exemplo nacional é a novela O Fascínio, de Tabajara Ruas.

\section{b) fantástica?}

R.: Uma literatura mais próxima das definições de Tzvetan Todorov do conto fantástico, e, portanto, mais perto de 
integrar o mainstream literário, do que a literatura popular ou de gênero. A literatura fantástica ressalta o desamparo do sujeito perante o absurdo da existência moderna, enquanto os gêneros populares ressaltam a sua agência - sempre pode haver uma solução na ciência, na magia ou no sobrenatural (que muitas vezes funcionam como tecnologias). No fantástico estão mais E. T. A. Hoffmann, Guy de Maupassant, Franz Kafka, Jorge Luiz Borges, Salman Rushdie, Murilo Rubião e José J. Veiga, do que os suspeitos usuais da FC e da fantasia: Asimov, Clarke, Gibson, Heinlein, Le Guin, Tolkien, Howard, Moorcock e Martin. "Literatura fantástica" se tornou um rótulo vinculado à $\mathrm{FC}$, à fantasia e ao horror no Brasil apenas por descuido conceitual ou por estratégia disfarçada de conferir respeitabilidade aos gêneros populares. Tenho dito há tempos que minha preferência é "literatura especulativa" como um coletivo para FC, fantasia e horror. Isso também está no meu livro pela Editora UFMG.

\section{c) cientifica?}

R.: Uma ficção que busca especular sobre a realidade num sentido mais amplo ou ontológico (o que ela é ou não é), a partir de conceitos de ciência e tecnologia.

\section{d) de horror?}

R.: Uma ficção que busca especular sobre a realidade num sentido, a partir de conceitos paranormais ou sobrenaturais.

\section{e) de fantasia (fantasy)?}

R.: Uma ficção que busca especular sobre a realidade, a partir de conceitos mágicos ou sobrenaturais. 
P.: E como o ficcionista Roberto de Sousa Causo rotularia, para o leitor comum, as ficções gótica, fantástica, científica, de horror, de fantasia (fantasy)?

R.: Da mesma maneira. Acho que o leitor - qualquer que seja, e certamente um leitor elitista teria as mesmas dificuldades de aceitação desses conceitos que um leitor que enxerga esses gêneros apenas como diversão - deve ter maturidade suficiente para se relacionar com a FC, a fantasia e o horror nesses termos, se quiser extrair o melhor deles. A ficção especulativa não se limita a ser escapista, ela tem o potencial de mostrar que o aqui e o agora são contingentes e precários.

P.: O que você pensa que vai ser o futuro dessas vertentes ficcionais neste nosso mundo globalizado e midiatizado?

R.: A tendência delas é a de viverem as suas vidas intensas, mutantes e agitadas, como sempre viveram, mas agora com a certeza de que são gêneros escritos e publicados no mundo todo, exigindo uma abertura cada vez maior tanto de editores, quanto de leitores e críticos. Há hoje uma FC e fantasia de grande intensidade de produção tanto na África, Ásia e América do Sul, quanto na América do Norte e na Europa. Essa produção carrega com ela elementos de localidade muito interessantes e perturbadores da corrente principal da ficção especulativa ela mesma precisando ser chacoalhada. Ao mesmo tempo, no contrafluxo desse crescimento, existe a tendência de se limitar o leque de temas e abordagens, promovida justamente pelo cinema e televisão (e os videogames) de circulação mundial. É uma das razões de eu acreditar na importância do retorno a 
uma pesquisa das raízes e evolução desses gêneros, juntamente com o esforço consciente de atualizá-los para as questões do momento (como Clive Bloom afirmou em Cult Fiction, a ficção pulp, ou popular, se caracteriza por uma intensa figuração do contemporâneo) e de adaptá-los para o contexto particular (brasileiro). É nesse programa que se encontram tanto a minha pesquisa quanto a minha produção literária. Agir localmente, pensando globalmente - mas na esperança de também contribuir para uma prática que hoje é global. 